\title{
Synthesis of Copper Nanoparticles on Cellulosic Fabrics and Evaluation of their Multifunctional Performances
}

\section{Veerender Sharma}

Indian Institute of Technology Delhi

\section{Santanu Basak}

NIRJAFT: National Institute of Research on Jute and Allied Fibre Technology

Wazed Ali ( $\square$ wazed@iitd.ac.in )

Indian Institute of Technology Delhi https://orcid.org/0000-0001-8253-5022

\section{Research Article}

Keywords: copper nanoparticles, cotton, 4 nitroaniline (4 NA), phenylene diamine(4 PD), catalysis, SEM, antimicrobial activity

Posted Date: June 22nd, 2021

DOI: https://doi.org/10.21203/rs.3.rs-613183/v1

License: (c) (i) This work is licensed under a Creative Commons Attribution 4.0 International License. Read Full License 


\section{Abstract}

Two different kinds of copper nanoparticles (CuNPs) (brown colour and greenish colour) were synthesised by using simple solution route and applied on cotton by exhaust method to achieve multidimensional functionalization on one of the most popular cellulose materials e.g., cotton fabric. The synthesised CuNPs imparted different colours to cotton textile due to different conditions of synthesis and localized surface plasmon resonance. Physico-chemical characterizations of the synthesized nanoparticles were performed by using scanning electron microscope (SEM) and EDX analysis whereas the optical properties of the nanoparticles were studied using UV-visible spectroscopy. The prepared CuNPs of both the types demonstrated very good antimicrobial activity up to $97 \%$. In addition, cotton fabric treated with CuNPs showed very high catalytic activity for reduction of 4-nitroaniline in presence of sodium borohydride to phenylene diamine. Washing durability and rubbing fastness of the treated fabric have also been measured by following standard testing methods and found to be very good with a rating 4.

\section{Introduction}

Recent advancement in nanomaterials plays a major role in science and technology. Nanomaterials have been used in various applications such as sensor, catalyst, energy storage, energy harvesting and many more (Sharma et al. 2016; Chawla et al. 2017; Bairagi et al. 2019, Bairagi et al. 2020, Bairagi et al. 2020, Bairagi et al. 2020;). Numerous techniques have been used in the recent past to apply nanomaterials on different natural substrate for useful value addition. Treatment and functionalization of cotton with natural material and application of nanomaterial to textile attracted extensive attention, with the aim of imparting various functional properties such as flame retardancy using bulk as well as nanomaterial (Shukla et al.2019; Alongi et al. 2014; Alongi and Malucelli et al 2015; Sharma et al.2018; Durani et al 2020), hydrophobicity (Leng et al. 2009), ultra-violet-protection (Dhineshbabu et al. 2016; Shaheen et al. 2016) and antimicrobial (Sedighi et al. 2014; El-Shishtawy et al. 2011; Mohamed et al. 2017) properties. Different methods of application have been developed to achieve different functionalities by exploring different nanoparticles. Among them, electrostatic assembly, chelation by active groups, plasma treatment and in situ synthesis are most common and much explored process route for generation or synthesis of nanoparticles (Alongi et al. 2014; Cady et al. 2011; Dong and Hinestroza et al. 2009; Gorjanc et al. 2010; Tang et al.2012, 2013).

Among the mostly available and explored nanoparticles, copper nanoparticles (CuNPs) attract more attention due to their low production costs and they are free from toxicity. Copper complexes and metallic copper have been used from centuries in various processes such as disinfection of liquid, solid, and human tissues, etc. (Perelshtein et al. 2013). Copper based materials have been used in heat transfer systems (Eastman et al. 2001) as antimicrobial agents (Esteban-Cubillo et al. 2006; Cioffi et al. 2005a, b), sensors (Kang et al. 2007; Male et al. 2004; Xu et al. 2006), as an excellent-resistant material (Wang et al. 2002; Kang et al. 2007) and as catalysts. Recently, various types of nanoparticles have been applied on the fabric to impart multifunctionalities on cellulose (like catalyst, antimicrobial, coloration, self-cleaning, 
ultraviolet ray protection, etc.). In the same way, cellulosic materials also attract more attention for the application of nanoparticles due to their exceptional biocompatibility, no or low toxicity, and potential biological activities (Mary et al. 2009). Various scientific techniques have been reported on the synthesis route of copper nanoparticles including gas-phase evaporation, vacuum vapor deposition, chemicalmechanical, hydrothermal radiation, ultrasonic, reverse microemulsion, electrolysis, electron beam irradiation, sol-gel, and mostly used chemical reduction methods, (Cheng et al. 2006) etc. As per report, chemical reduction technique used for the synthesis of nanoparticles has certain advantages of tuning the process parameters such as the $\mathrm{pH}$, temperature, stabilizing agent, reducing agent, and solvent quantity. As a result, particle size of the synthesized material can be controlled in a proper manner and also the process provides a grip for addressing the aggregation challenge of nuclei (Wang and Gao et al. 2007). ZnO nanoparticles were used in organic Knoevenagel reaction in coumarins synthesis as a single pot green synthesis (Vinay et al.2011) whereas silver nanoparticles were used as catalyst in reduction, coupling and various aspects in synthesis of a variety of fine chemicals (Dong et al.2015). So, nanoparticles are also gaining a lot of interest in synthesis and transformation of various organic moieties as emerging field.

In present method, CuNPs were synthesised and applied on commodity cotton textile by using exhaust process. On the other hand, copper salt used for the nanoparticle formation is cheaper (as compared to silver and gold salt) and thus the entire process is an affordable and sustainable approach for value added product development. Nanoparticles like Ni/ZnSn(OH) ${ }_{6}$, Nickel/Zinc hydroxy stannate were used for reduction of 4 nitroaniline to phenylene diamine (Mohamed et al. 2014) but the concerned nanoparticles are quite expensive and have adequate effect on environment. Contrary, CuNPs play a major role in electro catalysis of p-nitro aniline and reduces 4 NA efficiently to 4 PD. Two types of copper nanoparticles were synthesised in the present study and both have showed remarkable efficiency to reduce 4 NA. This may be due to smaller size of the synthesized CuNPs which exhibit large surface area for the catalysis and render higher catalytic activity than other ones. Synthesized CuNPs also have showed very good antimicrobial activity, good coloration on cotton textiles having wonderful washing and rubbing fastness properties.

\section{Experimental}

\section{Materials}

Copper sulphate $\left(\mathrm{CuSO}_{4} \cdot 5 \mathrm{H}_{2} \mathrm{O}\right)$, phenylene diamine, sodium hydroxide $(\mathrm{NaOH}$, Assay-98\%), 4-nitroaniline, and sodium borohydride $\left(\mathrm{NaBH}_{4} 98 \%\right)$ were purchased from Merck, India. All chemicals used for the experimental purposes were of analytic-grade reagents and further purification was not required. Entire study was carried out on pure cotton cellulosic fabric of density of $118 \mathrm{~g} / \mathrm{m}^{2}$. Deionised water was used throughout the process.

\section{Synthesis Of Cunps On Cotton Fabric}


Synthesis of CuNPs on cotton fabrics was done by using direct solution route. Two types of CuNPs were prepared separately by addition of $240 \mathrm{mg}$ of disodium citrate, 0.01 molar solution of sodium borohydride to $100 \mathrm{ml} 0.01$ molar solution of copper sulphate in continuous stirring in one formulation and in second formulation additional $150 \mathrm{mg}$ of sodium hydroxide was added before addition of sodium borohydride solution. Disodium citrate was used as capping agent in both the cases, otherwise the synthesized CuNPs became agglomerated very fast and precipitated out. Afterwards, two pieces of cotton fabric $(25 \mathrm{~cm} * 15 \mathrm{~cm})$ were dipped into two formulations separately with a continuous stirring at $30^{\circ} \mathrm{C}$ for $10 \mathrm{~min}$. After that, the temperature of the reaction mass was increased to $80-90^{\circ} \mathrm{C}$ for $30 \mathrm{~min}$. Two types of colours were found to be developed on the fabric; one was light brown wherein there was no content of $\mathrm{NaOH}$ and second one was greenish copper nanoparticles where $\mathrm{NaOH}$ was added. The treated fabrics were rinsed with running deionized water twice and dried at room temperature. Thereafter the treated materials were finally dried further at oven at $100^{\circ} \mathrm{C}$ for $2 \mathrm{hrs}$. Samples obtained were named as Cot-Cu-1 (brown colour, without addition of $\mathrm{NaOH}$ ) and Cot-Cu-2. (greenish brown colour, with addition of $\mathrm{NaOH}$ ). Copper nanoparticles (CuNPs) were synthesized by reduction of copper sulphate solution using sodium borohydride solution wherein sodium borohydride acts as reducing agent. In case of gold nanoparticles, cellulose itself acts as reducing agent (Bin Tang 2017). It was also observed that at basic $\mathrm{pH}$, particles size of formed copper nanoparticles also gets decreased because sodium hydroxide itself acts as stabilizing agent. Light brown particles were formed when only sodium borohydride was used, while greenish coloured nanoparticles were formed when sodium borohydride was used in presence of sodium hydroxide at basic $\mathrm{pH}$ which is supported by SEM data.

\section{Functional Group Analysis Of The Fabric Treated With Cunps}

\section{Functional group analysis of treated and untreated sample was accomplished using a Fourier Transform IR spectroscopy (Thermofisher Scientific instrument, Model: Nicolet is50 FTIR). The samples were scanned in the range of 500 to $4500 \mathrm{~cm}^{-1}$ wave number.}

\section{Surface Morphology Of Nanoparticles And Treated Cotton Fabric}

The surface morphology of CuNPs prepared by both the routes and the treated cellulosic fabric with these nanoparticles was investigated by scanning electron microscope (SEM) (made by ZEISS EVO). 


\section{Colourfastness To Washing}

Washing fastness of the treated fabric samples was analysed in accordance with standard test. Cotton fabrics treated with CuNPs were washed at $50^{\circ} \mathrm{C}$ for $45 \mathrm{~min}$ in presence of ECE reference detergent $\left(4 \mathrm{gL}^{-}\right.$

$\left.{ }^{1}\right)$ using a Launder-o-meter. Gregteg Color i7 7000 spectrophotometer was used to record the values of lab colour coordinates $\left(L^{*}, a^{*}\right.$, and $\left.b^{*}\right)$ for the CuNPs treated samples before and after washing where $L^{*}$ represents the lightness/darkness, $a^{*}$ value corresponds to the red or green chroma, and $b^{\star}$ corresponds the chromaticity coordinate for yellow/blue.

\section{Colourfastness To Rubbing}

Rubbing fastness of CuNPs incorporated fabrics was analysed as per standard (AS 2001.4.15-2006). Fabric treated with CuNPs was rubbed using a ready for dyeing (RFD) cotton cloth. Grey scale was used to evaluate the staining on RFD cotton cloth.

\section{Catalytic Activity}

Catalytic activity of the CuNPs treated cotton fabric was analysed by monitoring the conversion of 4nitroaniline (4-NA) to 4-phenylene diamine (4-PD) in presence of $\mathrm{NaBH}_{4}$. Catalytic activity was performed in presence of untreated and treated fabric by using Shimadzu 2450 UV spectrophotometer. In a typical experiment, $2.0 \mathrm{~mL} \mathrm{NaBH} 4$ solution $(3.0 \mathrm{M})$ was added into $30 \mathrm{~mL}$ 4-NA aqueous solution $(0.025 \mathrm{mM})$. Subsequently, $30 \mathrm{mg}$ cotton fabric (Control cotton, Cot-Cu-1 to Cot-Cu-2) was added into the mixed solution of 4-NA and $\mathrm{NaBH}_{4}$ under vigorous stirring. UV-Vis absorption spectra were monitored during the conversion of 4-NP to 4-PD. Catalytic efficiency of treated fabrics was analysed using UV-Vis spectrophotometer.

\section{Tensile Strength Of The Fabric}

ASTM D5034, grab test method was used to evaluate the tensile strength of control and copper treated cotton fabrics using tensile testing machine (Tinius Olsen, Model: H5KS). Treated and untreated samples of dimension $200 \mathrm{~mm} \star 50 \mathrm{~mm}$ were analysed at a speed of $300 \mathrm{~mm} / \mathrm{min}$.

\section{Evaluation Of Antimicrobial Activity}

Antimicrobial activity of copper treated cotton samples was tested using standard colony counting method (AATCC 100). Digital colony counter was used to calculate the number of colonies of control and treated cotton fabrics and bacterial cell reduction (BCR) was calculated by using following formula: 
BCR \% = (No. of colonies in untreated sample - No. of colonies in treated sample) / No. of colonies in untreated sample

\section{Results And Discussion FTIR analysis}

FTIR spectra of raw and treated cotton fabric with copper nanoparticles were analysed. It was observed from the curve that some new peaks have been formed in the FTIR curve of the treated fabric, at about 1500 to $1700 \mathrm{~cm}^{-1}$. This phenomenon has been occurred may be because of the oxidation of cellulose due to reduction of copper ion. Cu nanoparticles treated cotton fabric (Cot-Cu-2) in presence of sodium hydroxide, shows less intense peak near this region. Tensile strength also follows the same order as strength got decreased due to oxidation of the treated cotton while the strength loss is even more in absence of sodium hydroxide. This observation substantiates that $\mathrm{Cu}$ nanoparticles get attached to cellulosic structure physically as well as chemically. Stretching observed around $1500-1700 \mathrm{~cm}^{-1}$ in the treated samples is due to oxidation of cellulose whereas $\mathrm{OH}$ stretching was observed in all three samples in region of $3,200-3,500 \mathrm{~cm}^{-1}$ (Sedighi et.al 2014.)

\section{Surface Morphology Of Copper Nanoparticles And Treated Fabric}

Synthesis of CuNPs on cotton fabric was performed by using direct solution route. As mentioned earlier, two types of CuNPs (cu nanoparticles) were prepared by addition of $100 \mathrm{mg}$ of disodium citrate, $0.01 \mathrm{M}$ solution of sodium borohydride to $100 \mathrm{ml} 0.01 \mathrm{~m}$ solution of copper sulphate in continuous stirring in one formulation and in second formulation additional $100 \mathrm{mg}$ of sodium hydroxide was added. Disodium citrate was used as capping agent for restricting the agglomeration or precipitation of synthesised nanoparticles. Thereafter, two pieces of cotton fabric were added to above mentioned formulation with continuous stirring at to $30^{\circ} \mathrm{C}$ for $10 \mathrm{~min}$. Thereafter, the reaction mass was heated to $80^{\circ} \mathrm{C}$ for $30 \mathrm{~min}$. At the end, the CuNPs (copper nanoparticles) treated fabrics were washed with running deionized water twice and dried at $30^{\circ} \mathrm{C}$ temperature for $10 \mathrm{~min}$. Further the treated fabric was dried at oven at $100^{\circ} \mathrm{C}$ for 2 hrs and samples obtained by following the method was Cot-Cu-1 and Cot-Cu-2. Average particle size of $400 \mathrm{~nm}$ was found to be formed on Cu-1 samples while average dimension of $300 \mathrm{~nm}$ particles was formed when sodium hydroxide was used which is mainly responsible for fast reduction of $p$ nitro amine to $p$-phenylene diamine.

From the surface morphology analysis, the uniform covering of the fabric surface by in-situ formation of nanoparticles was observed as depicted in Fig. 3. SEM figure clearly shows the uniform coating on both the treated fabrics with copper nanoparticles. 
The cotton fabric treated in first formulation (Cot-Cu-1) was light brown and in second formulation (Cot$\mathrm{Cu}-2$ ) was greenish, implying presence of CuNPs on the cotton fabric. The colour of the cotton fabric treated with CuNPs (Cot-Cu-2) has been changed from light brown to red to dark greenish brown as the sodium hydroxide was added to second formulation.

\section{Edx Analysis Of The Treated Sample}

Elemental analysis of both the treated samples was done using EDX analysis. It was observed that copper content gets increased on the fabric which was treated at basic $\mathrm{pH}$. This may be due to more swelling of the treated cotton at basic $\mathrm{pH}$ which helps to penetrate more copper nanoparticles inside the cotton fabric and supports faster reduction in Cot-Cu-2 sample than Cot-Cu-1 sample. Copper nanoparticles percentage was 1 in Cot-Cu-1 sample and 3\% in Cot-Cu-2 when applied at basic (pH 11) pH using sodium hydroxide. SEM EDX image also shows smaller particles in Cot-Cu-2 image than Cot-Cu-1 image in single thread which also justifies SEM analysis of the formed particles.

\section{Influence Of Ph Value}

The original $\mathrm{pH}$ value of the $\mathrm{CuSO}_{4}$ aqueous solution at $0.01 \mathrm{M}$ was around 2.8. It has been investigated that $\mathrm{pH}$ plays an important role in the formation of copper nanoparticles as without sodium hydroxide treated sample showed more strength loss than the sample treated in presence of sodium hydroxide. The

$\mathrm{pH}$ value of the reaction systems of Cot-Cu- 1 was around 2.8 as such and the Cot-Cu- 2 was 11 by addition $\mathrm{NaOH}$ aqueous solution. Two different colours have been generated after addition of sodium borohydride solution to above solutions due to the formation of different size nanoparticles.

\section{Assessment Of Colourfastness Of The Copper Treated Cotton}

Colourfastness is one of the important aspects to assess the properties and performance of the textile products. Cot-Cu-1 and Cot-Cu-2, both the treated fabric samples were tested for colourfastness to washing. Treated samples were washed by using Lissapol $\mathrm{N}$ detergent at $50^{\circ} \mathrm{C}$ for $45 \mathrm{~min} . \mathrm{L}, \mathrm{a}^{\star}, \mathrm{b}^{\star}, \mathrm{C}^{\star}$ and $\mathrm{h}^{\star}$ values of the treated fabric were measured before and after washing and the concerned data is represented in Table 1. Value obtained after wash clearly demonstrates that both the cotton fabrics coloured with CuNPs possess reasonably good colourfastness to washing. Treated fabrics also were examined for colour fastness to rubbing. The grey scale rating was used to demonstrate the DE values of Cot-Cu-1, Cot-Cu-2, under dry and wet rubbing conditions. The dry rubbing colour fastness was rated as 4 for both the treated fabrics whereas wet rubbing data for Cot-Cu-1 and Cot-Cu-2 are 3 and 3.5, respectively. Therefore, from the fastness data it could be confirmed that the copper treated fabrics retain copper particles even after laundering and rubbing. 
Table 1

Color value of the treated and washed cotton fabric

\begin{tabular}{|lllllll|}
\hline Sr No & & L & $\mathbf{a}^{*}$ & $\mathbf{b}^{*}$ & $\mathbf{C}^{*}$ & $\mathbf{H}$ \\
\hline 1 & Pure Cotton & 81.78 & -0.11 & 2.85 & 2.85 & 92.27 \\
2 & Cot-Cu-1 & 71.41 & 1.26 & 9.67 & 9.75 & 82.59 \\
\hline 3 & Cot-Cu-2 & 38.44 & -0.33 & 5.45 & 5.56 & 93.45 \\
\hline 4 & Cot-Cu-1 after wash & 77.13 & 1.69 & 7.07 & 7.27 & 76.53 \\
\hline 5 & Cot-Cu-2 after wash & 41.26 & -0.34 & 5.33 & 5.34 & 93.63 \\
\hline
\end{tabular}

\section{Investigation Of Catalytic Activity Of The Treated Fabric}

Metal and metal oxide nanoparticles have widely been used as catalyst in various applications from long back (Sharma et al. 2017). Metals have been used as reducing agent and its oxide have been exploited as oxidising agent (Sharma et al. 2017). Recently, silver (Ag), gold (Au) nanoparticles have been widely used by the researchers as catalyst in various organic reactions (El Shistawy et al. 2010, Tang et al. 2017). In the present research, CuNPs are bound to cotton fabrics after their synthesis at higher temperature and for the first time it has been used in the reduction of p-nitroaniline to p-PD as a model reaction, depicted in Fig. 4. UV absorption of standard 4NP and 4PD was also recorded. From the experimental analysis, it was clear that 4PD and 4NA absorb at different wavelength i.e., 300 and $380 \mathrm{~nm}$. Cellulose acts as support and after reaction CuNPs remain with cellulosic fabric and this copper functionalized cellulosic fabrics were again used for reduction.

CuNPs treated cotton samples showed catalytic activity which was monitored by UV-Vis absorption spectra of aqueous solution during reduction of 4-NP using $\mathrm{NaBH}_{4}$ using a UV-visible spectrophotometer. There was a change in colour of the 4-NP solution from light yellow to brown after reduction. In general nitro compounds are inert to $\mathrm{NaBH}_{4}$ in absence of catalyst. However, metal nanoparticles on cellulose fabric have acted as an electron transfer agent from $\mathrm{NaBH}_{4}$ to nitro compound to accelerate the reduction reaction (Barnes et al. 2003). Absorption peak observed at $300 \mathrm{~nm}$ in UV-vis absorption may be assigned with 4-PD and $380 \mathrm{~nm}$ in UV-Vis absorption may be denoted for 4-NP. It has also been observed that the absorption peak intensity at $300 \mathrm{~nm}$ was increased and peak intensity at $380 \mathrm{~nm}$ was decreased during the reaction in presence of the treated fabric. However, peak intensity remains almost same whatever has been observed for only 4-NP in presence of untreated sample. Further, it also has been observed that CuNPs treated sample in presence of sodium hydroxide shows more activity than without sodium hydroxide treated samples.

The absorption peak observed at $380 \mathrm{~nm}$ due to 4 nitroaniline was rapidly decreased due to excellent catalytic activities of CuNPs treated cotton fabrics. However, Cot-Cu -2 reduced 4 nitroaniline faster than the Cot-Cu-1 system whereas no reduction was observed in case of control cotton even after 24 hours. 4- 
NA reduction is generally considered to be a pseudo-first-order kinetic reaction on account of excess $\mathrm{NaBH}_{4}$ used. (Ai et al. 2012; Tang et al. 2017.

Figure5. UV-Vis spectra of (A) 4-nitroamine, $380 \mathrm{~nm}$, (B) phenylene diamine, $300 \mathrm{~nm}$, (C) (4-nitroamine $(380 \mathrm{~nm})$ and phenylene diamine $(300 \mathrm{~nm})$, (D) cellulose-Cu-1 nanoparticles used reduction at initial, 1, 3, $5,10,20,30,45,60 \mathrm{~min}$, (E) cellulose-Cu-2 nanoparticles at initial, 1, 3, 5 min.

\section{Mechanical Properties Of Treated Cotton Fabric}

Physical effect of copper nanoparticle integration on cotton fabrics was analysed by studying the tensile strength of control cotton and treated cellulosic fabrics. Pristine cellulosic fabric showed the tensile strength of around $635 \mathrm{~N}$ whereas CuNPs treated cotton fabric showed the tensile strength of around 314 $\mathrm{N}$ (Cot-Cu-1) and $614 \mathrm{~N}$ (Cot-Cu-2). CuNPs treated samples have adverse effect on the strength of the treated fabric while the treatment has been carried out in absence of sodium hydroxide (Cot-Cu- 1 in this case). However, the tensile strength has remained almost same in which the treatment was performed in presence of sodium hydroxide (Cot-Cu- 2 in this case). It also has been reported in literature that cellulosic fabric if treatment is done in basic $\mathrm{pH}$, then there should not be any detrimental effect on the fabric properties (Sharma el.at 2018). However, strength falls to remarkable extent is a known phenomenon once the treatment is done in acidic $\mathrm{pH}$. It is obvious that cotton gets degraded at acidic $\mathrm{pH}$ due to depolymerisation due to acid attack on chain of cellulose. In our case FTIR analysis also supports the same wherein there is a significant loss in tensile strength due to degradation of cellulosic structure as represented by increased formation of aldehyde groups after the treatment process (in case of Cot-Cu-1).

\section{Antimicrobial Activity Of The Treated Fabrics}

It is well known that the cellulosic materials are prone to attack by microorganisms, usually they act as accumulator, spreader, and multiply microorganisms in nearby environment (Dastjerdi and Montazer et al. 2010). It has already been reported in literature that cellulosic fabrics treated with various metal, metal oxide nanoparticles exhibit antibacterial properties (Sedighi et al. 2014.) The results of the antibacterial tests, represented in Table 2, demonstrate the excellent antibacterial efficacy of the cotton fabrics containing copper nanoparticles. Both the treated fabric samples exhibited an efficient antibacterial effect against Gram negative, E. coli bacteria. Table 2 represents the reduction of colonies of treated sample [Cu-Cot-1 and Cu-Cot-2] and BCR percentage with respect to control cotton sample. 
Table 2

Antimicrobial results of the control and the treated cotton fabrics

\begin{tabular}{|llll|}
\hline \multicolumn{3}{|c|}{ Antimicrobial test results against $E$. coli bacteria } \\
\hline Sr. No & Sample Description & No. of Colonies & BCR \% \\
\hline 1 & UNTREATED & 780 & \\
\hline 2 & Cot-Cu-1 & 18 & 97.69 \\
\hline 3 & Cot-Cu-2 & 24 & 96.92 \\
\hline
\end{tabular}

Antimicrobial activity of metal nanoparticles is a proven phenomenon which occurs in multiple mode as these can penetrate inside the cell wall of bacteria due to its very small size and eventually inhibit the activity of bacteria to multiply. Nano copper showed antibacterial activity due to various aspects as they can adhere to the cell wall of Gram-negative bacteria because of electrostatic force, disturb cell membrane protein structure, accelerate the process of denaturation of protein, etc. (Ali Sedighi 2014).

\section{Conclusions}

This research work represents in-situ synthesis of the two types of CuNPs on cotton fabrics. The fabric became coloured by application of the synthesized CuNPs. Two different types of colours (light brown and greenish) were obtained on the treated fabric. Both the fabrics treated with CuNPs showed catalytic activity, as measured by reduction of 4-NA to 4-PD. Greenish coloured cotton fabric showed more catalytic activity toward reduction of 4- nitroaniline. The mechanical property of cotton fabrics treated with CuNPs in absence of sodium hydroxide showed remarkable decrease in tensile strength of fabric treated (in acidic $\mathrm{pH}$ ), due to degradation of cellulosic structure. Both the treated fabrics showed an excellent antimicrobial efficacy against $E$. coli bacteria. SEM investigations showed homogeneous distribution of CuNPs on cotton fabric. The treated fabric also demonstrated good rubbing and colour fastness properties.

\section{Declarations}

\section{Competing financial interest}

The authors declare no competing financial interest.

\section{Human And Animal Rights}

This research article does not involve any human participants and/or animals for studies by any of the authors. 


\section{References}

1. Alongi J, Cuttica F, Blasio AD, Carosio F, Malucelli G (2014). Intumescent features of nucleic acids and proteins. Thermochim Acta, 591: 31-39.

2. Alongi J, Blasio AD, Milnes J, Malucelli G (2015). Thermal degradation of DNA, an all in one natural intumescent flame retardant. Polym Degrad Stabil., 113: 110-118.

3. Alongi J, Carosio F, Malucelli G (2014). Current emerging techniques to impart flame retardancy to fabrics: an over-view. Polym Degrad Stabil., 106:138-149.

4. Bairagi S, Ali SW, (2019). A unique piezoelectric nanogenerator composed of melt-spun PVDF/KNN nanorod-based nanocomposite fibre. Eur. Poly. J.,116: 554-561.

5. Bairagi S, Ali SW, (2020). Flexible lead-free SM-KNN/PVDF electrospun nanocomposite based piezoelectric materials: significant enhancement of energy harvesting efficiency of the nanogenerator. Energy, $198: 117385$.

6. Bairagi S, Ali SW, (2020). A hybrid piezoelectric nanogenerator comprising of $\mathrm{KNN} / \mathrm{ZnO}$ nanorods incorporated PVDF electrospun nanocomposite webs. Inter. J. Ener. Res., 44(7): 5545-5563.

7. Bairagi S, Ali SW (2020). Poly (vinylidine fluoride) (PVDF)/Potassium Sodium Niobate (KNN) nanorods based flexible nanocomposite film: Influence of KNN concentration in the performance of nanogenerator. Org. Electro.,78: 105547.

8. Cady NC, Behnke JL, Strickland AD (2011). Copper-based nanostructured coatings on natural cellulose: nanocom-posites exhibiting rapid and efficient inhibition of a multi-drug resistant wound pathogen, A. baumannii, and mam-malian cell biocompatibility in vitro. Adv Funct Mater, 21:25062514.

9. Chawla M, Sharma V, Randhawa JK (2017).Facile One Pot Synthesis of CuO Nanostructures and Their Effect on Nonenzymatic Glucose Biosensing. Electrocatalysis, (2017) 8:27-35.

10. Cheng X, Zhang X, Yin H, Wang A, Xu Y (2006). Modifier effects on chemical reduction synthesis of nanostructured copper. Appl. Surf Sci., 253:2727-2732.

11. Cioffi N, Ditaranto N, Torsi L, Picca RA, DeGiglio E, Sabbatini L, Novello L, Tantillo G, Bleve-Zacheo T, Zambonin PG (2005a). Synthesis, analytical characterization and bioactivity of Ag and Cu nanoparticles embedded in polyvinyl- methyl-ketone films. Anal Bioanal Chem.,41:5208-5212.

12. Dhineshbabu NR, Arunmetha S, Manivasakan P, Karunakaran G, Rajendran V (2016). Enhanced functional properties of cotton fabrics using TiO2/SiO2nanocomposites. J Ind Text., 45:674-692.

13. Dong H, Hinestroza JP (2009). Metal nanoparticles on natural cellulose fibers: electrostatic assembly and in situ synthesis. ACS Appl. Mater Interfaces, 1:797-803.

14. Dong XY, Gao ZW, Yang KF (2015). Nanosilver as a new generation of silver catalysts in organic transformations for efficient synthesis of fine chemicals. Catal. Sci. Technol., 5: 2554-2574.

15. Durrani H, Sharma V , Bamboria D ,Shukla A, Basak S , Ali SW(2020). Exploration of flame retardant efficacy of cellulosic fabric using in-situ synthesized zinc borate particles. Cellulose, 27:9061-9073. 
16. Eastman JA, Cho SU, Thompson LJ (2001). Anomalously increased effective thermal conductivity of ethylene glycol-based nanofluids containing copper nanoparticles. Appl. Phys Lett., 78:718-720.

17. El-Shishtawy RM, Asiri AM, Abdelwahed NAM, Al-Otaibi MM (2011). In situ production of silver nanoparticle on cotton fabric and its antimicrobial evaluation. Cellulose,18:75-82.

18. Esteban-Cubillo A, Pecharroman C, Agilar E, Santaren J, Moya J (2006). Antibacterial activity of copper monodispersed nanoparticles into sepiolite. J Mater Sci.,41:5208-5212.

19. Gorjanc M, Bukosek V, Gorensek M, Mozetic M (2010).CF4 plasma and silver functionalized cotton. Text Res J., 80:2204-2213.

20. Kumar BV, Naik HSB, Girija D and Kumar BV (2011). ZnO nanoparticle as catalyst for efficient green one-pot synthesis of coumarins through Knoevenagel condensation. J. Chem. Sci., 123, 5:615-621.

21. Kang X, Mai Z, Zou X, Cai P, Mo J (2007). A sensitive nonenzymatic glucose sensor in alkaline media with a copper nanocluster/multiwall carbon nanotube-modified glassy carbon electrode. Anal Biochem.,363:143-150.

22. Leng BX, Shao ZZ, de With G, Ming WH (2009). Superoleo- phobic cotton textiles. Langmuir, 25:2456-2460.

23. Mohamed AL, El-Naggar ME, Shaheen TI, Hassabo AG (2017). Laminating of chemically modified silan based nanosolsfor advanced functionalization of cotton textiles. Int J Biol. Macromol., 95:429437.

24. Male KB, Hrapovic S, Liu Y, Wang D, Luong JH (2004). Electrochemical detection of carbohydrates using copper nanoparticles and carbon nanotube. Anal Chim. Acta., 516:35-41.

25. Mary G, Bajpai SK, Chand N (2009). Copper (II) ions and copper nanoparticles-loaded chemically modified cotton cellulose fibers with fair antibacterial properties. J Applied Polymer Sci., 113:757766.

26. Perelshtein I, Ruderman Y, Perkas N, Beddow J, Singh G, Vinatoru M, Joyce E, Mason TJ, Blanes M, Molla' K, Gedanken A (2013). The sonochemical coating of cotton withstands 65 washing cycles at hospital washing standards and retains its antibacterial properties. Cellulose, 20:1215-1221.

27. Sedighi A, Montazer M, Hemmatinejad N (2014). Copper nanoparticles on bleached cotton fabric: in situ synthesis and characterization. Cellulose, 21:2119-2132.

28. Sharma V, Chawla M, Randhawa JK (2016). Enhanced sensitivity of nanostructured copper oxide for non-enzymatic glucose biosensing. Journal of the electrochemical society, 163(13):594-600.

29. Shaheen TI, El-Naggar ME, Abdelgawad AM, Hebeish A (2016). Durable antibacterial and UV protections of in situ synthesized zinc oxide nanoparticles onto cotton fabrics. Int J Biological Macromolecule, 83:426-432.

30. Sharma V, Basak S, Rishabh K, Umaria H, Ali SW (2018). Synthesis of zinc carbonate nanoneedles, a potential flame retardant for cotton textiles. Cellulose, 25:6191-6205.

31. Shukla A, Sharma V, Basak S, Ali SW (2019). Sodium lignin sulfonate: a bio-macromolecule for making fire retardant cotton fabric. Cellulose, 26:8191-8208. 
32. Tang B, Kaur J, Sun L, Wang X (2013). Multi functionalization of cotton through in situ green synthesis of silver nanoparticles. Cellulose, 20:3053-3065.

33. Tang B, Lin X,Zou F, Fan Y, Li. D , Zhou Ji, Chen Wu. Wang X (2017). In situ synthesis of gold nanoparticles on cotton fabric for multifunctional applications. Cellulose, 24:4547-4560.

34. Tang B, Zhang M, Hou X, Li J, Sun L, Wang X (2012). Coloration of cotton fibers with anisotropic silver nanoparticles. Ind Eng Chem Res., 51:12807-12813.

35. Wang XL, Gao QM (2007). Synthesis of copper (0) nanoparticles in nanoporous nickel phosphate VSB-1. Solid State Phenom.,121-123:479-482.

36. Xu Q, Zhao Y, Xu JZ, Zhu JJ (2006). Preparation of functionalized copper nanoparticles and fabrication of a glucose sensor. Sens Actuators B Chem.,114:379-386.

\section{Figures}

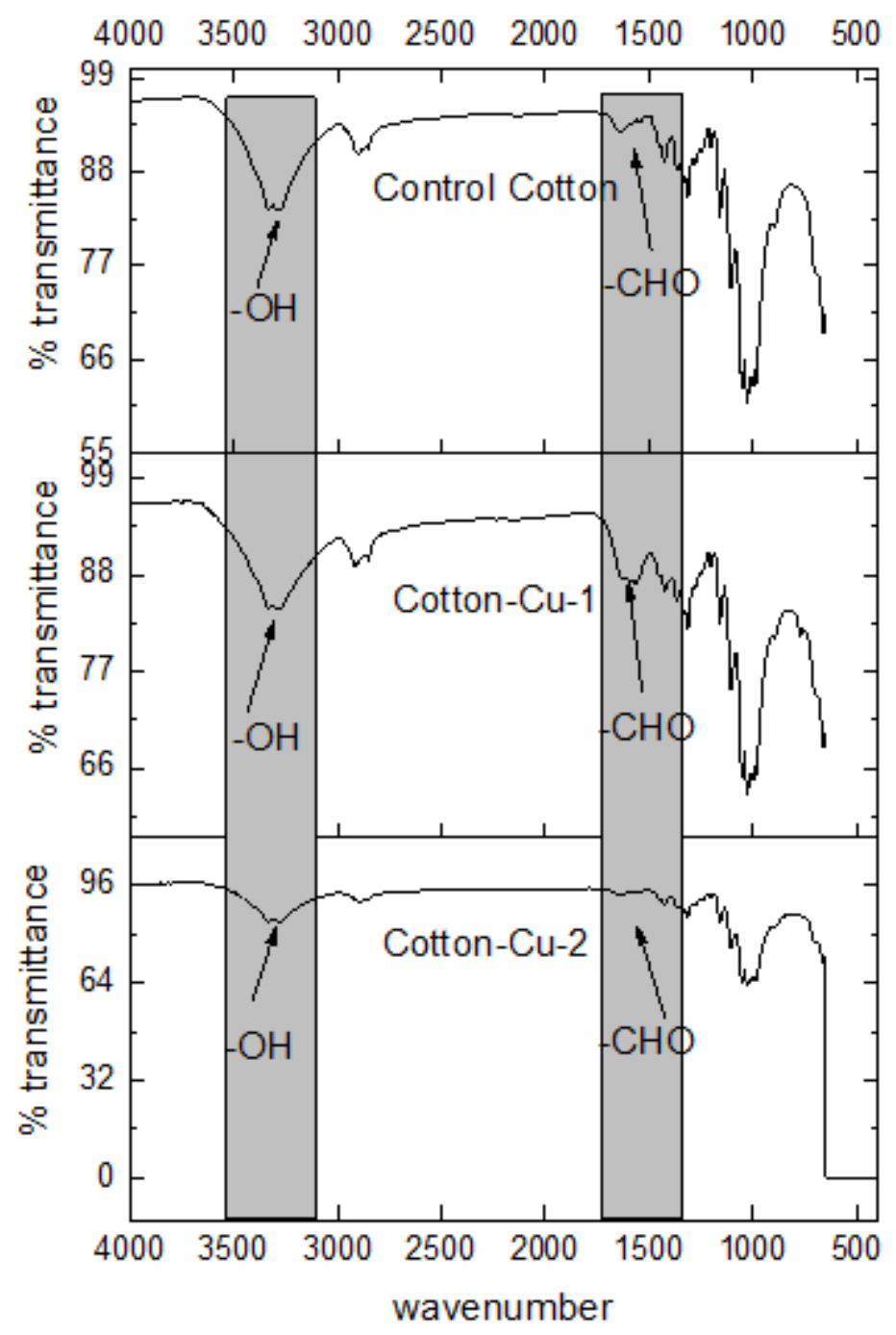

Figure 1

FTIR spectra of (A) control cotton, (B) Cot-Cu-1,(C) Cot-Cu-2 


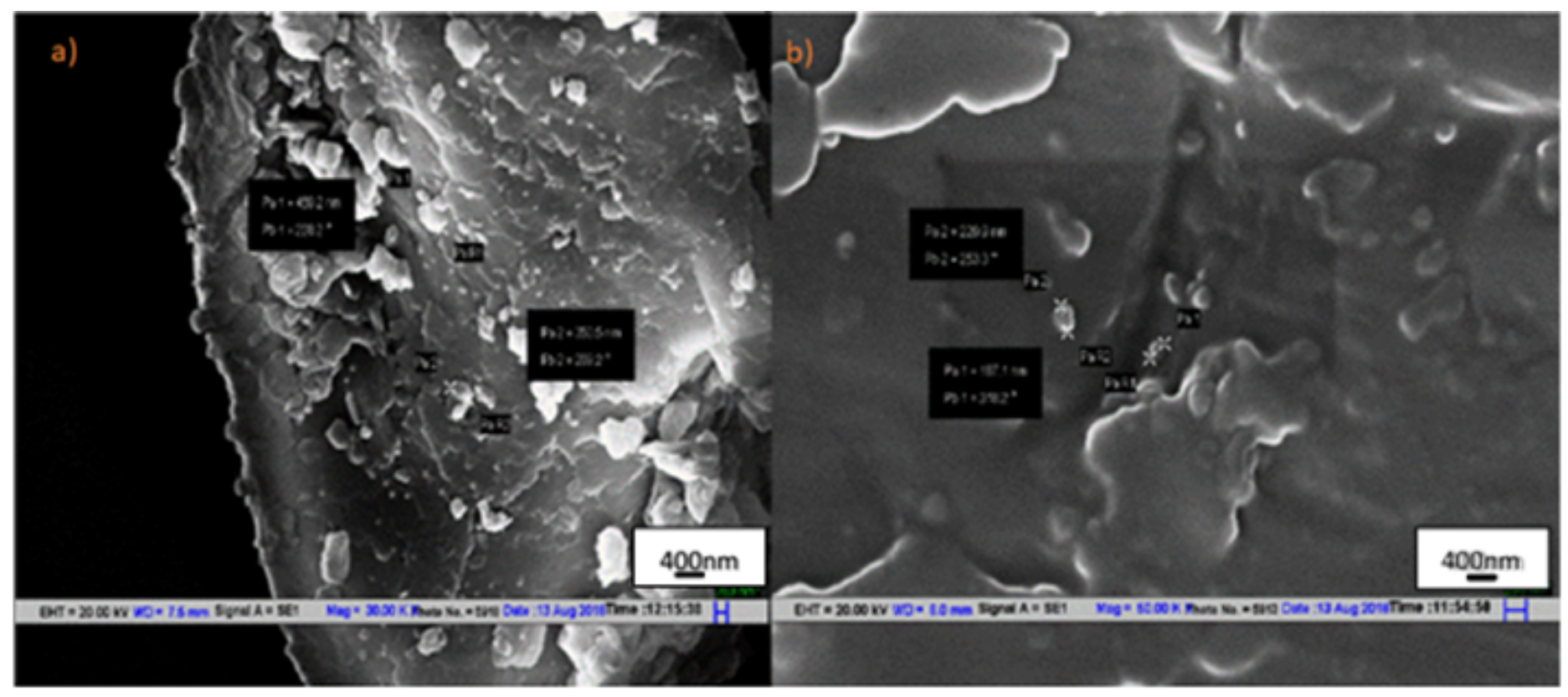

Figure 2

SEM image of (a) Cu-1 and (b) Cu-2 particles

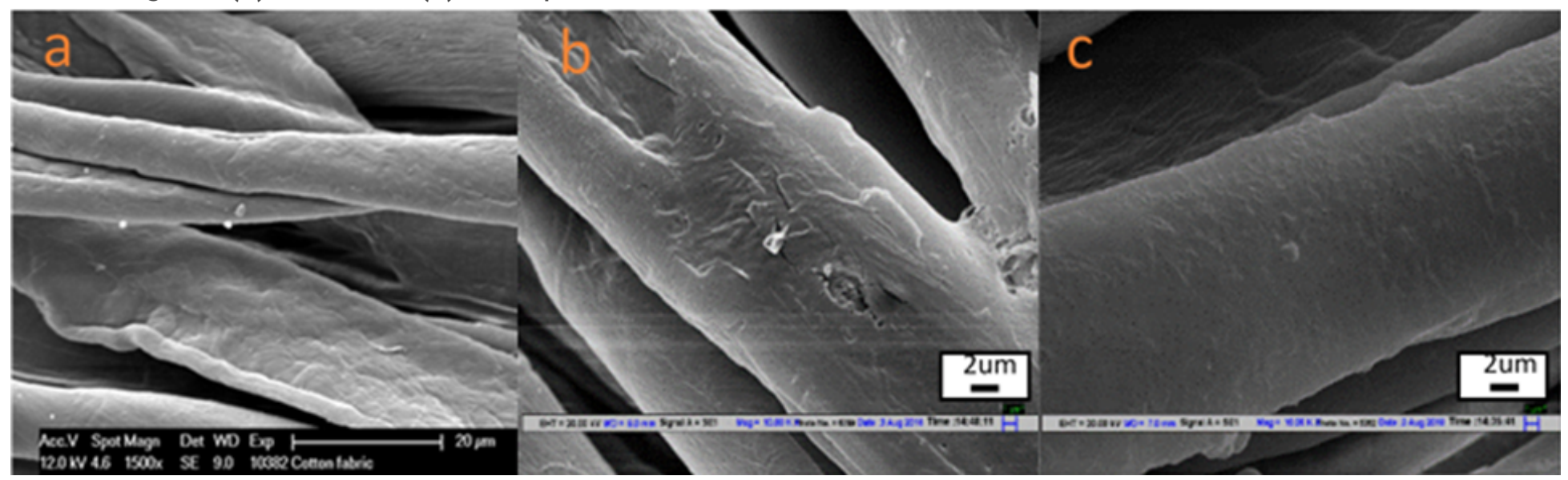

Figure 3

SEM images of (a)untreated cotton at magnification 1200x(b) Cot-Cu-1 at magnification 1000x and (c) Cot-Cu-2 at magnification $1000 x$ 

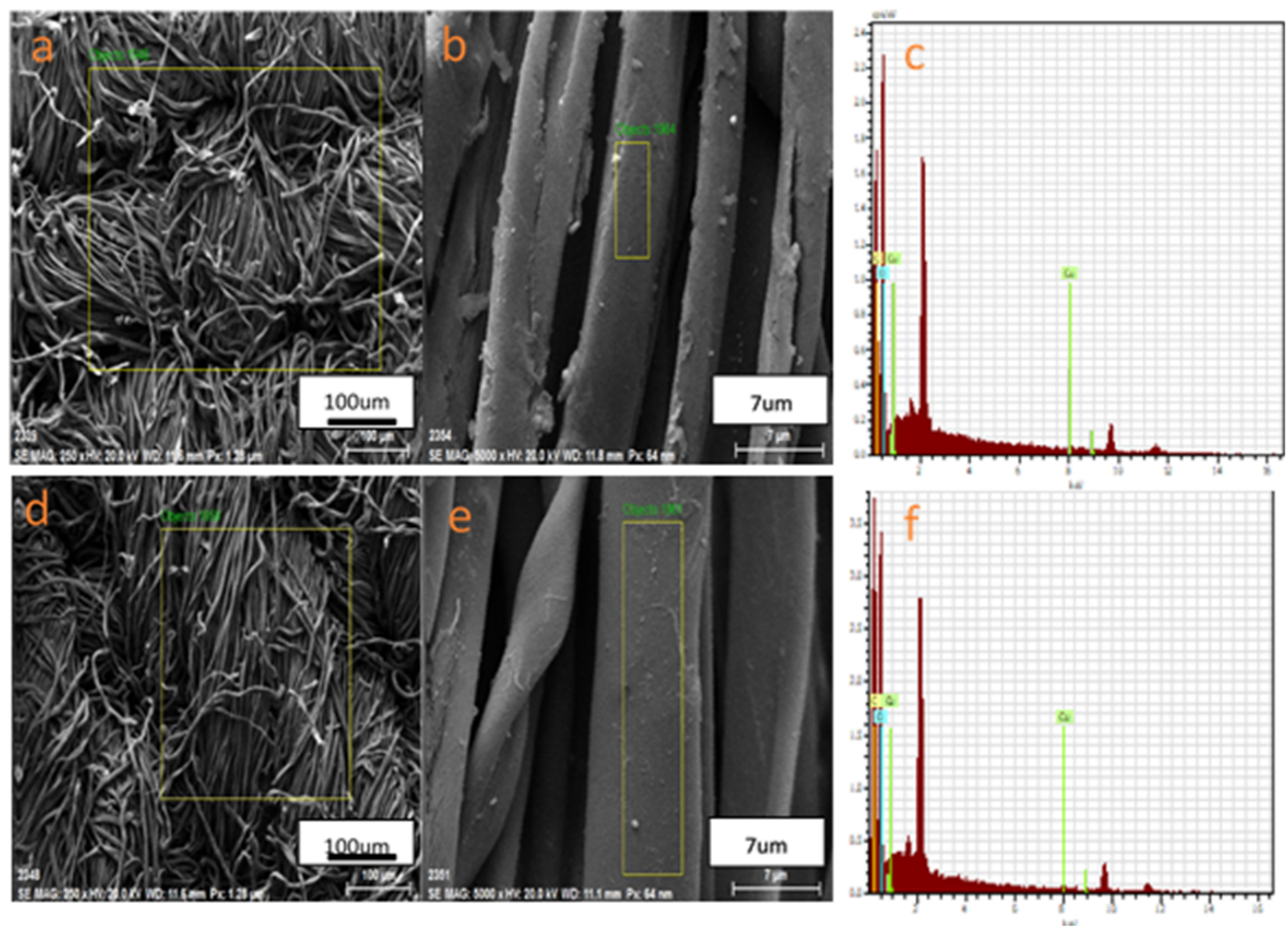

Figure 4

(a), (b), (c)show EDX of Cot-cu-1 taken at larger area and on single thread and (d), (e), (f) show EDX of Cot-cu-2 at larger area and single thread
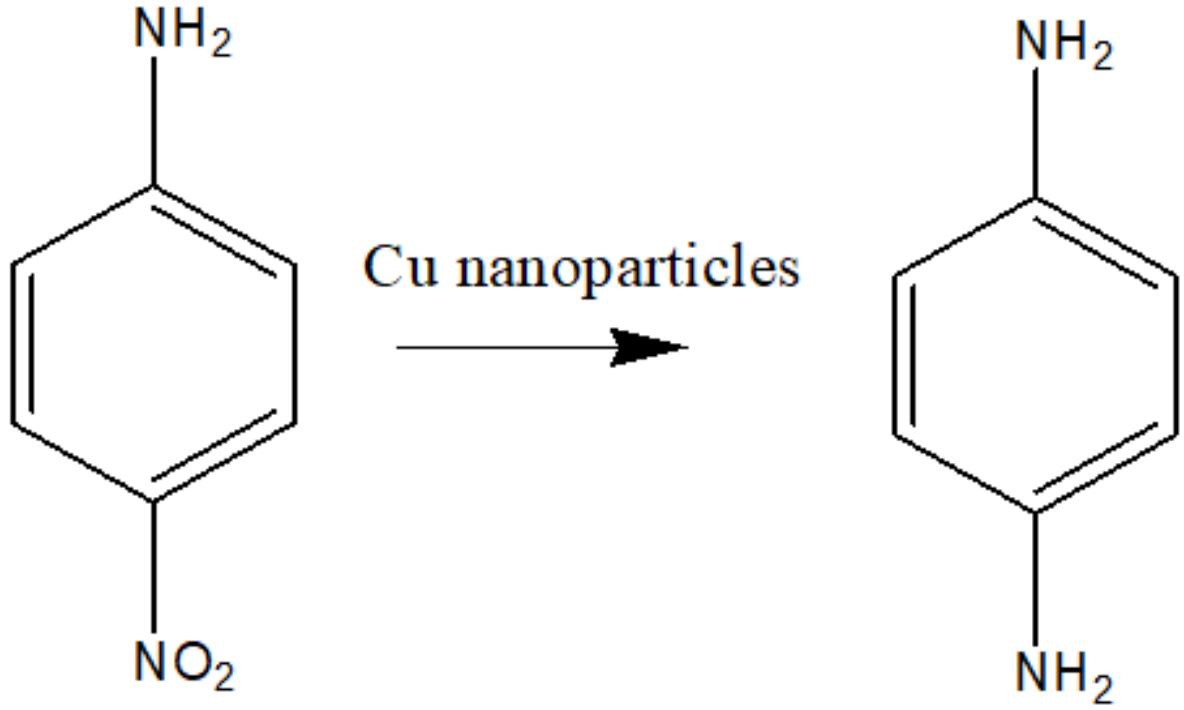
Figure 5

Representation of reduction reaction of 4-nitroaniline to phenylene diamine
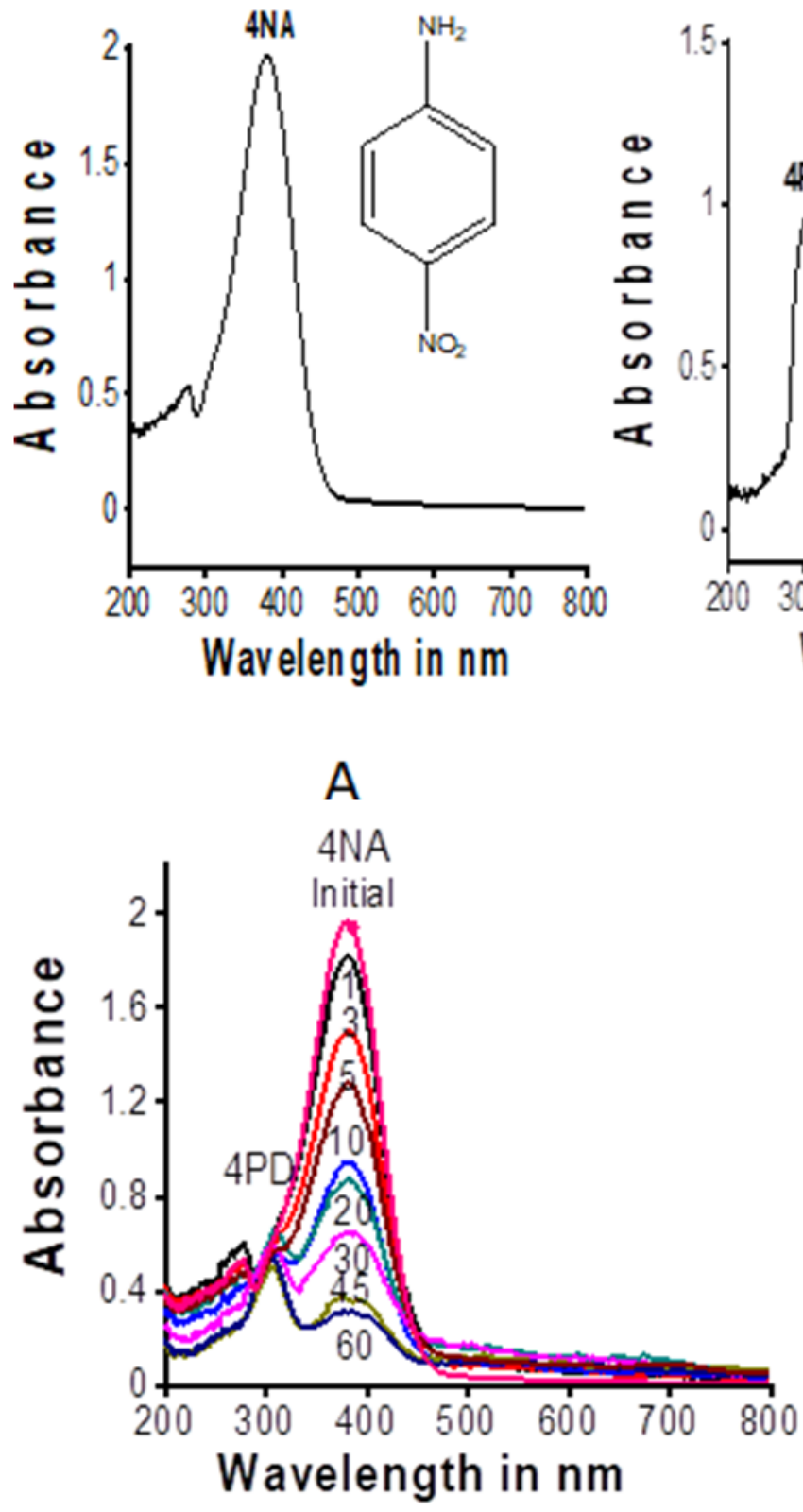

D

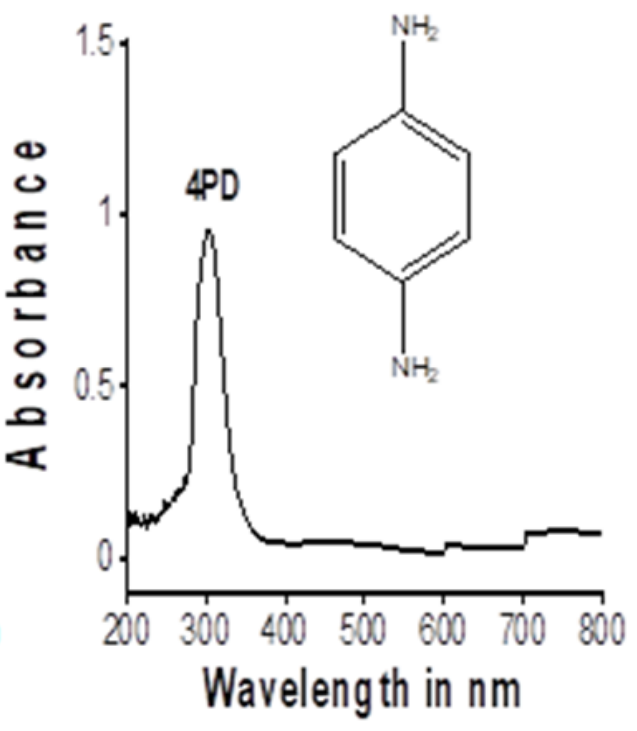

B

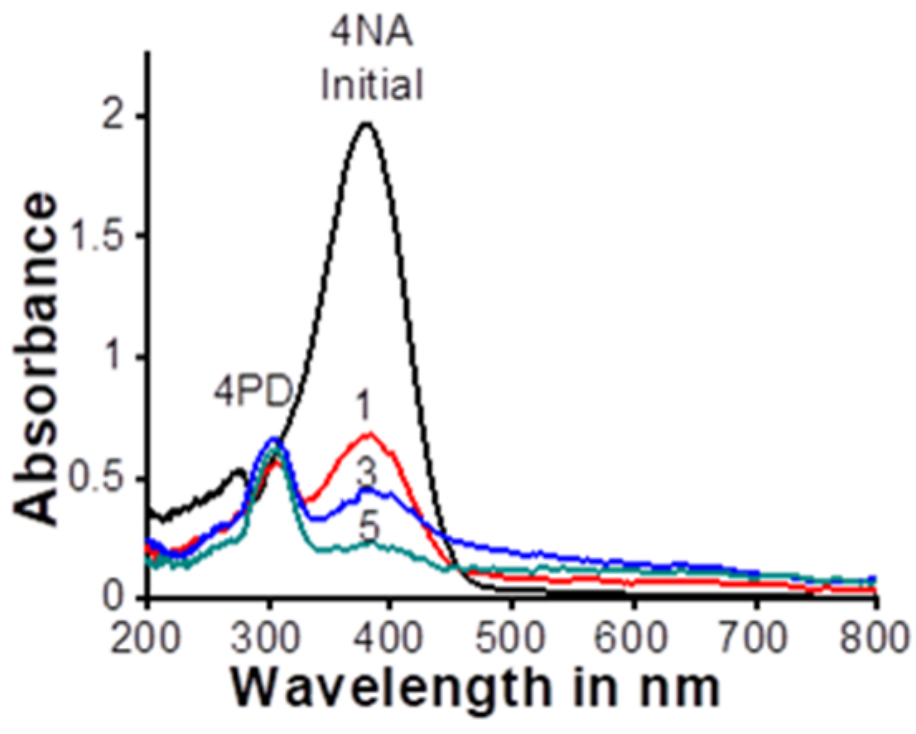

$\mathrm{E}$

Figure 6

UV-Vis spectra of (A)4-nitroamine,380nm,(B)phenylene diamine,300nm,(C)(4-nitroamine $(380 \mathrm{~nm})$ and phenylene diamine(300nm), (D) cellulose-Cu-1 nanoparticles usedreduction at initial,1,3,5,10,20,30,45,60 min,(E) cellulose-Cu-2 nanoparticles at initial,1,3,5min. 


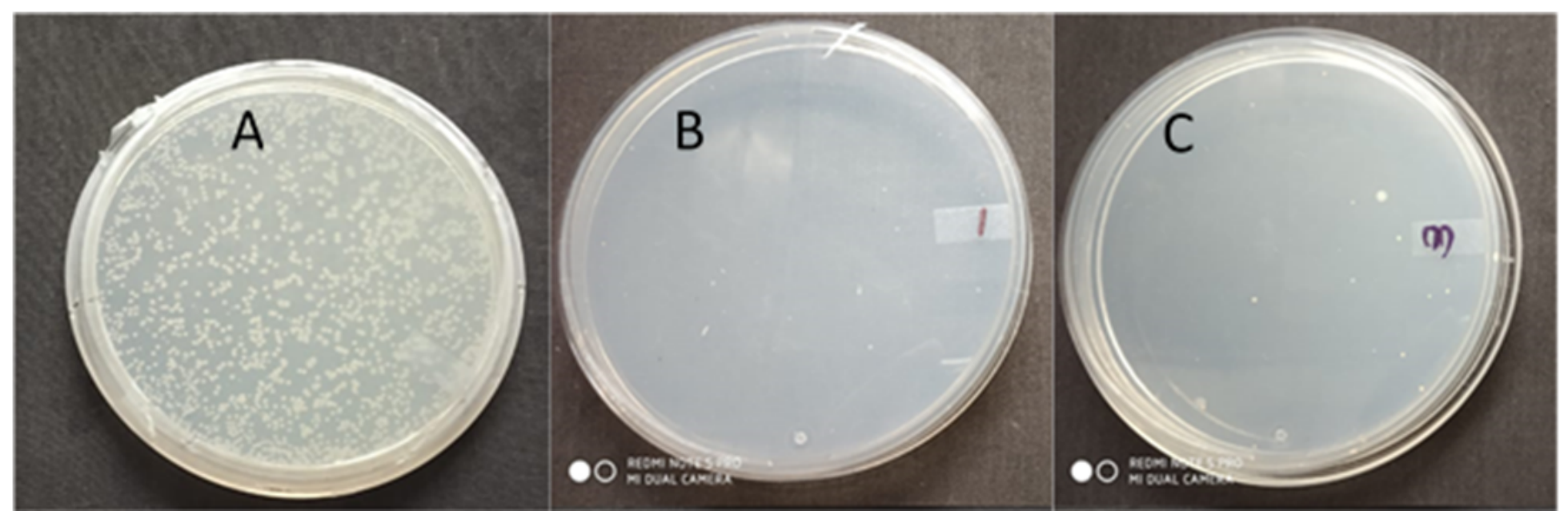

Figure 7

Bacterial colony growth onAgar plate (A)control cotton, (B) Cot-Cu-1, (C) Cot-Cu-2

\section{Supplementary Files}

This is a list of supplementary files associated with this preprint. Click to download.

- GraphicalAbstract.bmp 